\title{
Pesan Dakwah dalam Lirik Lagu Ebiet G. Ade
}

\author{
Syifa Hayati Islami \\ Jurusan Komunikasi dan Penyiaran Islam, Fakultas Dakwah dan Komunikasi, \\ UIN Sunan Gunung Djati, Bandung \\ *Email: syifahayati236@gmail.com
}

\begin{abstract}
ABSTRAK
Penelitian ini menggunakan pendekatan kualitatif yang bersifat wacana dokumentatif yang bertujuan untuk memaparkan makna ketauhidan yang terdapat dalam lirik lagu Ebiet G. Ade. Adapun lirik-lirik lagu tersebut adalah "Berita kepada kawan", "Untuk kita renungkan", "Masib ada waktu", "Aku ingin pulang", dan "Kepadamu Aku Pasrab". Ulubiyah Kemudian dianalisis menggunakan model analisis wacana Teun A Van Dijk. Hasil dari penelitian ini, terdapat tiga macam Tauhid yaitu: Tauhid, Tauhid Rububiyah dan Tauhid Ubudiyah. Dari keseluruhan lima lagu Ebiet G. Ade yang telah dianalisis yaitu terdapat tiga lagu yang mengandung makna Tauhid Ubudiyah, yaitu "Untuk Kita Renungkan", "Masih Ada waktu" dan "Kepadamu Aku Pasrab" satu lagu yang mengandung makna Tauhid Rububiyah, yaitu "Berita Kepada Kawan" dan satu lagu yang mengandung makna Tauhid Ulubiyah, yaitu "Aku Ingin Pulang".
\end{abstract}

Kata Kunci : Dakwah, Lirik Lagu, Analisis Wacana

\section{ABSTRACT}

This study uses a qualitative approach that is a documentary discourse that aims to explain the meaning of monoteism contained in the lyrics of the song Ebiet G. Ade. The lyrics of the song are "Berita kepada kawan", "Untuk kita renungkan", "Masih ada waktu", "Aku ingin pulang", and "Kepadamu Aku Pasrab". Then analyzed using Teun $A$ V an Dijk discourse analysis model. The results of this study, there are three kinds of Tawheed namely: Tawbeed Ulubiyah, Taubid Rububiyah and Taubid Ubudiyah. From all five songs of Ebiet $G$. Ade that have been analyzed that there are three songs that contain the meaning of Tawheed Ubudiyah, which is "Untuk Kita Renungkan", "Masih Ada waktu" dan "Kepadamu Aku Pasrab" a song that contains the meaning of Tawheed Rububiyah, namely "Berita Kepada Kawan" and one song that contains the meaning of Tawheed Ulubiyah, namely "Aku Ingin Pulang". 
Syifa Hayati Islami

Keywords: Dakwah, Song Lyrics, Discourse Analysis

\section{PENDAHULUAN}

Dakwah merupakan suatu bentuk proses penyampaian agama islam. Dakwah islam adalah dakwah ke arah kualitas puncak dari nilai-nilai kemanusiaan, dan peradaban manusia. (Muhammaad Al-Bahy, 1997: 45) Dengan utama mewujudkan kebahagiaan dan kesejahteraan hidup di dunia dan di akhirat yang di ridhai oleh Allah SWT., yakni dengan menyampaikan nilai-nilai yang dapat mendatangkan kebahagiaan dan kesejahteraan yang di ridhai oleh Allah SWT. sesuai dengan segi atau bidangnya masing-masing.

Lain halnya dengan kenyataan yang ada saat ini, kegiatan dakwah seringkali di artikan di tengah-tengah masyarakat hanya berupa ceramah agama yakni ulama sebagai pendakwah menyampaikan pesannya di hadapan khalayak. Sejatinya dakwah bukan hanya kewenangan ulama atau tokoh agama, karena dakwah Islam memiliki wilayah yang luas dalam semua aspek kehidupan. Ia memiliki ragam bentuk, metode, media, pesan, pelaku dan mitra dakwah. Kita sendiri tidak bisa terlepas dari kegiatan dakwah. Apapun yang berkaitan dengan Islam, kita pastikan ada unsur dakwahnya (Fatoni, 2014).

Salah satu dari unsur dakwah adalah materi dakwah. Materi dakwah adalah isi pesan yang disampaikan kepada mitra dakwah. Dalam hal ini pesan dakwah adalah ajaran islam itu sendiri. Inti ajaran agama islam adalah meliputu akidah, syari'ah dan akhlak. Akidah merupakan pondasi utama dalam beragama, yang didalamnya memuat sistem keyakinan atau iman. Syari'ah meliputi sistem peribadatan makhluk dengan khaliq-Nya, sedangkan akhlak meliputi sistem relasi antara makhluk dan makhluk.

Dalam rumusan lain, Dakwah diartikan sebagai proses internalisasi, transmisi, difusi, transformasi, dan aktualisasi penghambaan kepada Allah yang berkaitan dengan sesama manusia yang melibatkan da'i, maudhu, uslub, wasilah, dan mad'u dalam mencapai tujuan tertentu. Hal itu senada dengan Q.S. Al-Maidah: 67, An-Nahl: 44, 125; Al-Ahzab:45, 46; AlJum'ah:2. (Aep Kusnawan, 2009: 34)

Dari sejumlah pengertian di atas dapat disimpulkan, metode dakwah (ushlub al-dakwab) adalah segala cara menegakkan syari'at islam untuk mencapai tujuan dakwah yang telah ditentukan, yaitu terciptanya kondisi kehidupan mad'u yang al-salam, baik didunia maupun diakhirat nanti dengan menjalani syari'at islam secara murni dan konsekuen (Sukayat, 2009: 34).

Salah satu dari sekian banyak metode yang dapat ditempuh guna 
memenuhi tujuan tersebut adalah dengan merekontruksi dakwah yang dilakukan selama ini, sebab dakwah yang efektif membutuhkan pendekatan yang berubah-ubah serta metodologi yang sesuai dengan konteks zaman. Persepsi yang tebentuk dalam masyarakat selama ini bahwa kegiatan dakwah itu adalah kegiatan yang bersifat konvensional, di identikkan dengan mimbar, ceramah, pengajian rutin dari masjid satu ke masjid yang lain dan tabligh akbar. Padahal lebih jauh daripada itu terdapat lahan-lahan yang masih terbengkalai yang dapat digarap oleh para da'i dalam menyampaikan risalah Tuhan tadi, yaitu salah satunya dengan seni musik (Aripudin dan Ridwan, 2009).

Kesenian (seni musik) yang merupakan ekspresi dari keislaman itu mempunyai tiga karakteristik. Pertama, dapat berfungsi sebagai ibadah, takziah, tasbih, shadaqah dan sebagainya bagi pencipta dan penikmatnya. Kedua, menjadi identitas kelompok dan yang ketiga menjadi syi'ar (Kuntowijoyo, 2000: 209).

Pertama, seperti yang dikemukakan Sadali Almarhum, kesenian adalah tasbih. Memaha sucikan Allah secara individual dan secara kolektif bagi umat islam. Tidak seorang pun akan melihat ornamen dipucuk menara, barangkali hanya burung dan malaikat. Namun, orang nekat membuat ornamen setinggi itu, suatu kemubadziran. Tidak, memang itu tidak untuk manusia, tetapi semata-mata untuk mengagungkan asma Allah Azza wajalla. Kedua, memberi identitas. Takwa, iman, islam, dan shaleh tidak dapat dirasakan orang lain, sebab itu merupakan pengalaman yang sangat pribadi. Dengan kesenian, orang lain ikut merasakan pengalaman itu. Dengan kata lain, kesenian membuat konkret nilai-nilai yang semula abstrak itu. Ketiga syi'ar. Kesenian adalah alat komunikasi yang paling demokratis. Tidak ada paksaan untuk menonton, atau mendengar, atau menikmati. Melalui kesenianlah, dakwah menjadi sejuk,tidak dipaksakan dan secara tidak sengaja. Jadi, kesenian ada gunanya untuk dakwah, tetapi bukan sebagai alat. Mungkin festival, pawai, demonstrasi, rapat akbar, dan keramaian lain akan "memanaskan" suasana, namun itu tidak akan terjadi dengan kesenian.

Dalam Al-qur'an surat Ali-Imran (3): 110 ada pernyataan Allah yang umum, yaitu:

Kamu adalah umat yang terbaik yang dilahirkan untuk manusia, menyuruh kepada yang ma'ruf, dan mencegah dari yang munkar, dan beriman kepada Allah. Sekiranya ahli kitab beriman, tentulah itu lebih baik bagi mereka, di antara mereka ada yang beriman, dan kebanyakan mereka adalah orang-orang yang fasik. (Depag RI, 2004: 
Syifa Hayati Islami

64)

Memahami ayat di atas, Kuntowijoyo menjelaskan sebagaimana berikut ini:

Mari kita menggaris bawahi "menyuruh kebaikan", "mencegah kejahatan" dan "beriman kepada Allah. Atau, dengan bahasa yang lebih umum, lebih palatable untuk telinga modern, ketiganya adalah humanisasi (memanusiakan manusia). Liberalisasi (pembebasan dan transendensi (membawa manusia kepada Tuhan). Kita akan menyebut ketiganya dengan visi profetik mengenai peranan bersejarah umat islam. Sebab, itulah seluruh isi tugas kenabian (profhetic) dan kemanusiaan kita. Khusus untuk kesenian kita sebut Seni Profetik (Kuntowijoyo, 2000: 257).

Musik merupakan salah satu cabang yang sangat digemari oleh masyarakat kita yang telah sedemikian masuknya ke dalam kehidupan masyarakat. Musik telah mengibarkan bendera-benderanya di panggungpanggung kesenian, konser-konser, televisi, toko-toko, pusat-pusat perbelanjaan, kendaraan umum, di rumah, di kostan, bahkan dikantorkantor pada jam istirahat. Musik senantiasa menemani kegiatan manusia. Begitu juga dengan perkembangan teknologi rekaman dan alat-alat yang lebih canggih, yang menyebabkan semua orang dapat lebih mudah menikmati musik.

Musik dapat didefinisikan sebagai sebuah ekspresi perasaan atau pikiran yang dikeluarkan secara teratur dalam bentuk bunyi. Asal kata musik berasal dari bahasa yunani yaitu mousike yang diambil dari nama dewa dalam mitologi yunani kuno yaitu mousa yakni yang memimpin seni dan ilmu (Ensiklopedia Nasional Indonesia, 1990: 413).

Dari definisi diatas, dapat diketahui bahwa musik dapat menciptakan sebuah lagu. Sebuah lagu yang dinyayikan biasanya terdiri dari tiga komponen yang saling melengkapi dan saling bergantung. Komponen tersebut antara lain paduan alat musik atau instrumen, suara atau vokal dan lirik lagu. Instrumen dan kekuatan vokal penyanyi sebagai tubuh sedangkan lirik lagu adalah jiwa atau nyawa penggambaran musik itu sendiri.

Lirik lagu dalam musik sebagaimana bahasa dapat menjadi sarana atau media komunikasi untuk mencerminkan realitas sosial yang beredar dimasyarakat. Lirik lagu dapat pula sebagai sarana untuk sosialisasi dan pelestarian terhadap sikap atau nilai. Oleh karena itu, ketika sebuah lirik lagu diaransir dan diperdengarkan kepada khalayak juga mempunyai tanggung jawab yang besar dan tersebar luasnya keyakinan, nilai-nilai, 
bahkan prasangka tertentu (Setianingsih, 2003: 7-8).

Abid Ghoffar bin Aboe Dja'far atau yang lebih akrab disapa Ebiet G. Ade merupakan fenomena dari sekian banyak penyanyi yang menyematkan pesan-pesan ilahiyah dalam lagunya. Uniknya, Abid Ghoffar ini hadir membawakan lagu-lagu dengan suara khasnya yang keren pada genre balada. Pada umumnya, ada sebagian masyarakat yang memang mengganggap bahwa musik bergenre selain qoshidah/gambus itu identik dengan sisi negatif, syai'r-syai'r metal, lagu tak jelas dan sebagainya. Namun apabila kita telaah secara teliti sebenarnya itu hanya ulah oknum tertentu yang sebenarnya tidak mengetahui, tidak mau menghormati dan menghargai musik pada umumnya sebagai sebuah seni musik seperti musikmusik lainnya.

Selain itu dari keunikan lagu-lagu Ebiet G Ade bukanlah termasuk aliran musik manapun, akan tetapi merupakan jenis tersendiri, yaitu musikalisasi puisi, beliau sendiri yang menamakannya, yaitu cara membaca puisi yang dilagukan, atau puisi yang diberi musik. Hampir semua orang menyukai lagu lagu Ebiet $G$ Ade. Tidak seperti jenis musik lain seperti dangdut, rock, keroncong, walaupun banyak memiliki penggemar fanatik, namun selalu ada saja orang yang tidak menyukainya. Ya, mungkin karena musik dan keindahan lirik Ebiet G. Ade yang mampu menghipnotis para pendengarnya.

Maka dari itu kita tidak bisa menilai sebuah musik itu religi atau bukan hanya dilihat dari pelaku atau oknumnya saja (penyanyi), tapi juga nilai-nilai dan pesan moral yang ada dalam syair dari lagu tersebut. Sementara irama yang mengalun dalam setiap musik juga memiliki ciri khas masing-masing. Karena pada hakikatnya tidak semua lagu-lagu kasidah yang berbahasa arab itu juga mengandung nilai-nilai dakwah karena syai'r-syai'nnya juga banyak yang bertemakan tentang cinta lebay dan perselingkuhan. Dan disamping itu kita tidak bisa menganggap paten bahwa semua lagu kasidah atau lagu yang berabahasa arab itu mengandung nilai-nilai dakwah.

Dalam menulis lagu pada umumnya pengarang menggunakan bahasa yang indah atau bahasa yang khas, sehingga lagu yang diciptakan mempunyai nilai lebih yang bisa dilihat dari bahasanya. Dalam hal ini pengarang menggunakan bahasa yang mudah dipahami dan diterima sehingga karangan isinya dalam sebuah lagu mudah untuk diketahui maksudnya. Penelitian ini ingin mengetahui bagaimana perumusan masalah sekaligus mempertegas ruang lingkup objek yang diteliti. Ada tiga masalah yang dibahas dalam penelitian ini. Diantaranya: 1). Bagaimana struktur 
Syifa Hayati Islami

makro pada lirik lagu Ebiet G Ade? 2). Bagaimana super struktur pada lirik lagu Ebiet G Ade? Dan 3). Bagaimana struktur mikro pada lirik lagu Ebiet G Ade?.

Adapun Metode yang digunakan pada penelitian ini adalah metode analisis wacana yaitu sebuah reaksi terhadap bentuk linguistik tradisional yang bersifat formal (linguistik stuktural). Linguistik tradisional ini memfokuskan kajiannya pada pilihan unit-unit dan stuktur-stuktur kalimat tanpa memperhatikan analisis bahasa dalam penggunaannya. Berbeda dari linguistik tradisional, analisis wacana justru lebih memperhatikan hal-hal yang berkaitan dengan stuktur pada level kalimat, misalnya hubungan ketatabahasaan. Bagi teks tertulis, analisis wacana yang dilakukan bertujuan untuk mengeksplisitkan norma-norma dan aturan-aturan bahasa yang implisit. Selain itu, analisis wacana juga bertujuan untuk menemukan unitunit hierarkis yang membentuk suatu stuktur diskursif (Milies dalam Sobur, 2004: 35).

Untuk menganalisis dalam memahami isi lirik lagu, maka peneliti menggunakan teori elemen wacana Teun A. Van dijk. Teori yang digunakan Van dijk ini kerap disebut dengan "kognisi sosial" istilah itu sebenarnya diambil dari pendekatan lapangan psikolog sosial terutama untuk menjelaskan strukur dan proses terbentuknya suatu teks. Nama pendekatan ini seperti tidak lepas dari karakteristik yang diperkenalkan oleh Van dijk. Ia melihat suatu wacana terdiri atas berbagai struktur/tingkatan yang masing-masing bagian saling mendukung .

Van Dijk membagi struktur teks ke dalam tiga tingkatan. Pertama, struktur makro. Ini merupakan makna global/ umum dari suatu teks yang dapat diamati dengan melihat topik atau tema yang dikedepankan dalam suatu berita. Kedua, superstruktur. Ini merupakan struktur wacana yang berhubungan dengan kerangka atau skema suatu teks, bagaimana bagian-bagian teks tersusun ke dalam berita secara utuh. Ketiga, struktur mikro adalah makna wacana yang dapat diamati dari bagian kecil dari suatu teks yakni kata, kalimat, parafrase dan lain-lain.

Pemakaian kata-kata tertentu, kalimat, gaya tertentu bukan semata dipandang sebagai cara berkomunikasi melainkan sebagai politik berkomunikasi, suatu cara untuk mempengaruhi pendapat umum, menciptakan dukungan, memperkuat legitimasi, dan menyingkirkan lawan atau penentang. Struktur wacana adalah cara yang efektif untuk melihat proses retorika dan persuasi yang dijalankan ketika seseorang menyampaikan pesan. 


\section{LANDASAN TEORITIS}

Secara etimologis, menurut para ahli bahasa, dakwah berakar kata da'a yad'u da'watan, artinya "mengajak" atau "menyeru". Secara terminologis, dakwah adalah mengajak atau menyeru manusia agar menempuh kehidupan ini di jalan Allah Swt. Berdasarkan ayat Alquran:

Serulah (manusia) kepada jalan Tuhan-mu dengan hikmah dan pelajaran yang baik dan bantahlah mereka dengan cara yang baik. Sesungguhnya Tuhanmu Dialah yang lebih mengetahui tentang siapa yang tersesat dari jalan-Nya dan Dialah yang lebih mengetahui orangorang yang mendapat petunjuk. (QS. An-Nahl: 125)/(Depag RI, 2004: 281)

Setiap perkataan, pemikiran, atau perbuatan yang secara eksplisit ataupun implisit mengajak orang ke arah kebaikan (dalam persfektif Islam), perbuatan baik, amal saleh atau menuju kebenaran dalam bingkai ajaran Islam dapat disebut dakwah.

Pengertian lirik dalam Kamus Besar Bahasa Indonesia adalah 1 karya sastra (puisi) yg berisi curahan perasaan pribadi, 2 susunan kata sebuah nyanyian. Menurut Nooryan Bahari (2008: 59), lirik atau puisi adalah seni yang cenderung menyederhanakan deskripsi dengan menangkap inti permasalahan yang ingin diungkapkan, dinyatakan, dicita-citakan dan sebagainya.

Lirik lagu adalah ekspresi tentang sesuatu hal yang dilihat atau didengar seseorang atau yang dialaminya. Dengan melakukan permainan kata serta bahasa untuk menciptakan daya tarik dam kekhasan terhadap lirik lagu yang dilakukan oleh seorang pencipta lagu.

Seperti permainan vokal gaya bahasa dan penyimpangan makna kata merupakan permainan bahasa dalam menciptakan lirik lagu. Selain itu juga notasi musik dan melodi yang disesuaikan dengan lirik digunakan untuk memperkuat lirik, sehingga pendengar semakin terbawa dengan apa yang dipikirkan pengarangnya (Awe: 2003).

Definisi lirik atau syair Lagu dapat dianggap sebagai puisi begitu pula sebaliknya dan sesuai dengan Jan van Luxemburg (1989) seperti definisi mengenai teks-teks puisi tidak hanya mencakup jenis-jenis sastra melainkan juga ungkapan yang bersifat iklan, pepatah, semboyan, doa -doa dan syair lagu pop.

Harus diketahui apa yang dimaksud dengan puisi bila definisi lirik lagu dianggap sama dengan puisi. Puisi menurut Rachmat Djoko Pradopo 
Syifa Hayati Islami

(1990) merupakan rekaman dan interpretasi pengalaman manusia yang penting dan digubah dalam wujud yang berkesan.

Sedangkan menurut Herman J. Waluyo (1987) mengatakan puisi adalah bentuk karya sastra yang mengungkapkan pikiran dan perasaan penyair secara imajinatif dan disusun dengan mengkonsentrasikan semua kekuatan bahasa pada struktur fisik dan struktur batinnya.

Maksudnya bahasa yang digunakan harus dibedakan dengan bahasa sehari-hari atau bahkan bahasa ilmiah dan bahasa yang digunakan penuh ambiguitas dan memiliki segi ekspresif yang justru dihindari oleh ragam bahasa ilmiah dan bahasa sehari-hari (Awe, 2003).

Karena sifat yang ambigu dan penuh ekspresi ini menyebabkan bahasa sastra cenderung untuk mempengaruhi, membujuk dan pada akhirnya mengubah sikap pembaca (Wellek \& Warren, 1989). Hubungan antara unsur musik dengan unsur syair atau lirik lagu merupakan salah satu bentuk komunikasi massa dari lagu yang terbentuk, dan lagu oleh komunikator kepada komunikan dalam jumlah yang besar melalui media massa berfungsi sebagai media penyampaian.

Mentauhidkan Allah adalah merupakan hal terpenting dari agama Islam, yakni menetapkan ke-Esa-an Allah, baik dzat, sifat, maupun perbuatan-Nya. Tauhid juga merupakan kewajiban pertama yang diperintahkan oleh Allah kepada hamba-Nya, dan merupakan awal dan akhir dari agama Islam, serta merupakan inti lahir maupun batin dari agama Islam. Lebih lanjut Ali bin Abi Thalib menjelaskan bahwa hal yang paling pertama dalam agama Islam adalah mengetahui (ma'rifat) Allah dan sempurna-sempurnanya ma'rifat kepada Allah adalah membenarkan dan meyakini-Nya (tashdiq), dan tashdiq yang paling sempurna adalah menge-Esa kan Allah (tauhid) dengan ikhlas.

\section{HASIL DAN PEMBAHASAN}

Abid Ghoffar bin Aboe Dja'far atau lebih dikenal dengan nama Ebiet G. Ade (lahir di Wanadadi, Banjarnegara, Jawa Tengah, 21 April 1954; umur 62 tahun) adalah seorang penyanyi dan penulis lagu berkewarganegaraan Indonesia. Ebiet dikenal dengan lagu-lagunya yang bertemakan alam dan duka derita kelompok tersisih. Lewat lagu-lagunya yang ber-genre balada, pada awal kariernya, ia memotret suasana kehidupan Indonesia pada akhir tahun 1970-an hingga sekarang. Tema lagunya beragam, tidak hanya tentangcinta, tetap ada juga lagu-lagu bertemakan alam, sosial-politik, bencana, religius, keluarga, dan lain-lain. Sentuhan musiknya sempat 
mendorong pembaruan pada dunia musik pop Indonesia. Semua lagu ditulisnya sendiri, ia tidak pernah menyanyikan lagu yang diciptakan orang lain, kecuali lagu "Surat dari Desa" yang ditulis oleh Oding Arnaldi dan "Mengarungi Keberkahan Tuhan" yang ditulis bersama dengan Presiden Susilo Bambang Yudhoyono.

Terlahir dengan nama Abid Ghoffar bin Aboe Dja'far di Wanadadi, Banjarnegara, merupakan anak termuda dari 6 bersaudara, anak Aboe Dja'far, seorang PNS, dan Saodah, seorang pedagang kain. Dulu ia memendam banyak cita-cita, seperti insinyur, dokter, pelukis. Semuanya melenceng, Ebiet malah jadi penyanyi kendati ia lebih suka disebut penyair karena latar belakangnya di dunia seni yang berawal dari kepenyairan.

Nama Ebiet didapatnya dari pengalamannya kursus bahasa Inggris semasa SMA. Gurunya orang asing, biasa memanggilnya Ebiet, mungkin karena mereka mengucapkan A menjadi E. Terinspirasi dari tulisan Ebiet di bagian punggung kaus merahnya, lama-lama ia lebih sering dipanggil Ebiet oleh teman-temannya. Nama ayahnya digunakan sebagai nama belakang, disingkat AD, kemudian ditulis Ade, sesuai bunyi penyebutannya, Ebiet G. Ade. Kalau dipanjangkan, ditulis sebagai Ebiet Ghoffar Aboe Dja'far.

\section{Struktur Makro Unsur Dakwah tentang Ketauhidan}

Menurut Van Dijk melihat suatu wacana terdiri atas berbagai struktur/tingkatan, yang masung-masing bagian saling mendukung. Vandijk membaginya dalam tiga tingkatan: Struktur makro, ini merupakan makna global/umum dari suatu teks yang dapat dipahami dengan melihat topik dari suatu teks. Tema wacana ini bukan hanya isi, tetapi juga sisis tertentu dari suatu peristiwa. Superstruktur adalah kerangka suatu teks: bagaimana struktur dan elemen wacana itu disusun dalam teks secara utuh. Struktur mikro adalah makna wacana yang dapat dengan menganalisis kata, anak kalimat, paraphrase yang dipakai dan sebagainya (Alex Sobur, 2009: 73-74). Pada tingkatan struktur makro, hal yang diamati adalah tematik dan elemennya adalah topik. Kata topik berasal dari kata Yunani topoi yang berarti tempat (Alex Sobur, 2009: 75)

Seperti yang dikutip oleh Alex Sobur dalam buku yang sama yaitu Analisis Teks media (2009: 75), "Teun A Van Dijk mendefinisikan topik sebagai struktur makro dari suatu wacana. Dari topik, kita bisa mengetahui masalah dan tindakan yang diambil oleh komunikator dalam mengatasi suatu masalah". Pada penelitian ini yaitu unsur dakwah dalam lirik lagu 
Syifa Hayati Islami

terdapat satu pokok tema tunggal yaitu ketauhidan.

Aspek pokok dalam ilmu Tauhid adalah keyakinan akan eksistensi Allah Yang Maha Sempurna, Maha Kuasa, dan memiliki sifat-sifat kesempurnaan lainnya. Adapun ruang lingkup pembahasan pesan dakwah dalam lirik lagu tentang ketauhidan ini yaitu hal-hal yang berhubungan dengan Allah SWT. atau mabda. Dalam bagian ini termasuk pula masalah takdir. Penjelasan pokok atau topik makro ini adalah mengenai Tauhid. Dalam Kamus Besar Bahasa Indonesia kata tauhid merupakan kata benda yang berarti keesaan Allah; kuat kepercayaan bahwa Allah hanya satu. Perkataan tauhid berasal dari bahasa Arab, masdar dari kata wahhada (وحد) yuwahhidu (يوحد) Secara etimologis, tauhid berarti keesaan. Maksudnya, keyakinan bahwa Allah SW'T. adalah Esa;Tunggal;satu. Pengertian inisejalan dengan lirik-lirik lagu Ebiet G.Ade, yaitu "keesaan Allah"; yang berarti mentauhidkan berarti juga "mengakui akan keesaan Allah;mengeesakan Allah" dalam pesan dakwahnya melalui lirik-lirik lagunya.

Pertama, super struktur pesan dakwah tentang ketauhidan. Manurut Van Dijk seperti yang dikutip Eriyanto (2006: 232) menyatakan: meskipun membentuk dan skema yang beragam, berita pada umumnya secara hipotetik mempunyai dua kategori skema besar. Pertama, Summary yang umumnya ditandai dengan dua elemen, yakni Lead. Kedua, story yakni isi berita secara keseluruhan. Contohnya, sebagai berikut:

\section{Lirik Lagu 1}

Lead : "Berita Kepada Kawan"

Body : Perjalanan ini

Trasa sangat menyedihkan

Sayang engkau tak duduk

Disampingku kawan

Banyak cerita

Yang mestinya kau saksikan

Di tanah kering bebatuan

Tubuhku terguncang

Dihempas batu jalanan

Hati tergetar menatap kering rerumputan

Perjalanan ini pun

Seperti jadi saksi

Gembala kecil 
Menangis sedih ...

Kawan coba dengar apa jawabnya

Ketika di kutanya mengapa

Bapak ibunya tlah lama mati

Ditelan bencana tanah ini

Sesampainya di laut

Kukabarkan semuanya

Kepada karang kepada ombak

Kepada matahari

Tetapi semua diam

Tetapi semua bisu

Tinggal aku sendiri

Terpaku menatap langit

Barangkali di sana ada jawabnya

Mengapa di tanahku terjadi bencana

Mungkin Tuhan mulai bosan

Melihat tingkah kita

Yang selalu salah dan bangga dengan dosa-dosa

Atau alam mulai enggan

Bersahabat dengan kita

Coba kita bertanya pada

Rumput yang bergoyang

Kedua, struktur mikro pesan dakwah tentang ketauhidan. Struktur mikro terdiri dari analisis linguistik, yakni semantik, sintaksis, stlitistik, dan retoris. Pertama, Semantik (detil, maksud, pra-anggapan). Semantik dalam skema van Dijk dikategorikan sebagai makna lokal (local meaning), yakni makna yang muncul dari hubungan antar kalimat, hubungan antarposisi yang membangun makna tertentu dalam suatu hubungan teks (Alex Sobur, 2001: 78)

Analisis makna dalam suatu lirik lagu dengan kajian semantik dimulai dari analisis kata-kata yang tersusun di dalamnya. Semantik yakni disiplin linguistik yang membahas secara mendalam tentang sistem makna (Pateda, 2010: 65). Artinya bahwa dalam semantik, bahasa dikaji dari segi makna. Entah makna berdasarkan struktural, ataupun citraan. Dimana citraan sangat relatif, tergantung sudut pandang pemahaman seseorang.

Dalam penelitian ini, yang menjadi objek adalah lirik lagu "Berita kepada kawan", "Untuk kita renungkan", "Masib ada waktu", "Aku ingin pulang", dan "Kepadamu Aku Pasrab" yang akan dikaji dalam salah satu cabang 
Syifa Hayati Islami

ilmu Linguistik yaitu Semantik. Dimana akan dikaji lebih dalam tentang makna yang terkandung pada setiap deretan kata yang tersusun di dalamnya. Sehingga dapat dipaparkan dan dijelaskan makna apa yang ingin disampaikan penciptanya, mungkin juga terdapat amanat atau pesan tersirat di dalamnya namun tak diketahui oleh pendengar.

Maka dalam kajian ini pendengar akan mendapatkan banyak informasi, selain pengetahuan tentang ilmu bahasa juga tentunya makna lirik-lirik lagu tersebut. Analisis dalam lagu ini hanya menyangkut makna. Karena pada dasarnya Semantik adalah salah satu cabang linguistik yang membahas tentang makna suatu kata. Maka dalam penelitian ini hanya tentang apa makna yang terkandung dalam lirik-lirik lagu Ebiet G. Ade, dengan tujuan yang tak lain adalah mengungkap makna ketauhidan pada lagu tersebut.

Kedua, Detil. Menurut Teun A Van Dijk dalam Eriyanto, 2011: 238 bahwa elemen wacana detil berhubungan dengan kontrol informasi yang ditampilkan seseorang. Komunikator akan menampilkan secara berlebihan informasi yang menguntungkan dirinya atau citra yang baik. Sebaiknya ia akan menampilkan informasi.

Ketiga, Maksud. Menurut Teun A Van Dijk dalam Eriyanto, 2011: 240 bahwa elemen wacana maksud, hampir sama dengan elemen detil, informasi yang menguntungkan komunikator akan diuraikan secara eksplisit dan jelas. Sebaliknya, Informasi yang merugikan akan diuraikan secara tersamar, implisit dan tersembunyi. Tujuan akhirnya adalah publik hanya disajikan informasi yang menguntungkan komunikator

Keempat, Pra-anggapan. Menurut Teun A Van Dijk dalam Eriyanto, 2011: 256 bahwa elemen wacana praanggapan (presupposition) merupakan pernyataan yang digunakan untuk mendukung makna suatu teks kalau latar berarti upaya maka praanggapan adalah untuk mendukung pendapat dengan memberikan premis yang dipercaya kebenarannya.

Menurut penulis bahwa dalam menganalisis lirik lagu, maka yang sangat dianjurkan hanyalah pada elemen semantik saja. Bukan berarti tak ada gunanya pada elemen detil, maksud dan praanggapan, namun elemenelemen tersebut sebenarnya sudah terwakili oleh adanya elemen semantik.

Ketiga, Sintaksis (Bentuk kalimat, koherensi, kata ganti). Sintaksis adalah studi mengenai hubungan kata dengan kata dalam membentuk satuan yang lebih besar, yaitu frase, klausa, dan kalimat (Abdul Chaer, 2002: 8-9). Elemen-elemen yang terdapat dalam sintaksis adalah bentuk kalimat, koherensi, dan kata ganti. Untuk meneliti sintaksis yang terdapat dalam 
pesan dakwah dalam lirik lagu berdasarkan elemen-elemen tersebut akan diuraikan sebagai berikut: Pertama, Bentuk kalimat. Sebagaimana dalam tabel di bawah ini:

Tabel 1: Bentuk kalimat aktif dan pasif

\begin{tabular}{|c|c|c|}
\hline Lirik & $\begin{array}{l}\text { Bentuk } \\
\text { kalimat }\end{array}$ & Asal kalimat \\
\hline 1 & Pasif & Perjalanan ini terasa sangat menyedihkan \\
\hline 1 & Pasif & sayang engkau tak dudukDisamping ku kawan \\
\hline 1 & Pasif & $\begin{array}{l}\text { Tubuhku terguncang } \\
\text { Dihempas batu jalanan }\end{array}$ \\
\hline 1 & Pasif & Hati tergetar menatap kering rerumputan \\
\hline 1 & Aktif & $\begin{array}{l}\text { Perjalanan ini pun } \\
\text { Seperti jadi saksi } \\
\text { Gembala kecil } \\
\text { Menangis sedih }\end{array}$ \\
\hline 1 & Pasif & $\begin{array}{l}\text { Kawan coba dengar apa jawabnya } \\
\text { Ketikadi kutanya mengapa }\end{array}$ \\
\hline 1 & Pasif & $\begin{array}{l}\text { Bapak ibunya tlah lama mati } \\
\text { Ditelan bencana tanah ini }\end{array}$ \\
\hline 1 & Pasif & $\begin{array}{l}\text { Kukabarkan semuanya } \\
\text { Kepada karang kepada ombak } \\
\text { Kepada matahari } \\
\text { Tetapi semua diam } \\
\text { Tetapi semua bisuTinggal aku sendiri } \\
\text { Terpaku menatap langit }\end{array}$ \\
\hline 1 & Aktif & $\begin{array}{l}\text { Mungkin Tuhan mulai bosan } \\
\text { Melihat tingkah kita } \\
\text { Yang selalu salah dan bangga dengan dosa-dosa }\end{array}$ \\
\hline 1 & Pasif & $\begin{array}{l}\text { Coba kita bertanya pada } \\
\text { Rumput yang bergoyang }\end{array}$ \\
\hline 2 & Pasif & $\begin{array}{l}\text { Tengoklah ke dalam sebelum bicara } \\
\text { Singkirkan debu yang masih melekat }\end{array}$ \\
\hline 2 & Aktif & $\begin{array}{l}\text { Anugerah dan bencana adalah kehendakNya } \\
\text { Kita mesti tabah menjalani }\end{array}$ \\
\hline 2 & Aktif & $\begin{array}{l}\text { Anak menjerit-jerit, asap panas membakar } \\
\text { Lahar dan badai menyapu bersih } \\
\text { Ini bukan hukuman, hanya satu isyarat } \\
\text { Bahwa kita mesti banyak berbenah }\end{array}$ \\
\hline 2 & Aktif & Tuhan pasti telah memperhitungkan \\
\hline
\end{tabular}


Syifa Hayati Islami

2

3

3

3

3

3

4

4

5
Amal dan dosa yang kita perbuat

Kemanakah lagi kita kan sembunyi

Hanya kepadaNya kita kembali

Kita mesti berjuang memerangi diri

Bercermin dan banyaklah bercermin

Tuhan ada di sini di dalam jiwa ini

Berusahalah agar

Dia tersenyum

Aktif Bila masih mungkin kita menorehkan batin

Atas nama jiwa dan hati tulus ikhlas

Mumpung masih ada kesempatan buat kita

Mengumpulkan bekal perjalanan abadi

Kita pasti ingat tragedi yang memilukan

Kenapa harus mereka yang tertimbun tanah

Tentu ada hikmah yang harus kita petik

Atas nama jiwa mari heningkan cipta

Kita mesti bersyukur

Bahwa kita masih diberi waktu

Kita masih bertemu matahari

Kepada rumpun di lalang kepada bintang gemintang

Kita dapat mencoba meminjam catatanNya

Sampai kapankah gerangan

Waktu yang masih tersisa

Semuanya menggeleng

Semuanya terdiam

Semuanya menjawab tak mengerti

Yang terbaik hanyalah segeralah bersujud

Kemanapun aku pergi

Bayang bayangmu mengejar

Bersembunyi dimanapun

S'lalu engkau temukan

Aku merasa letih dan ingin sendiri

Aku mencari jawaban di laut

Ku sadari langkah menyusuri pantai

Aku merasa mendengar suara

Menutupi jalan

Menghentikan petualangan

Kemanapun aku pergi

Selalu ku bawa bawa

Perasaan yang bersalah datang menghantuiku

Masih mungkinkah pintumu ku buka

Dengan kunci yang pernah kupatahkan

Lihatlah aku terkapar dan luka

Dengarkanlah jeritan dari dalam jiwa

KepadaMu aku pasrahkan

Seluruh jiwa dan ragaku 
Hidup dan mati ada di tanganMu

Bahagia, sedih ada di jariMu

5

Aktif

Cukup lama aku mencari

Menembus pekat dan menerjang kelam

Menyusuri langkah yang makin jauh

Adalah firmanMu pemandu jalanku

5

Aktif

Meski angin geram menerpa

Batu karang tak hendak terhempas

Meski ombak menerjang terjang

Rindu keteguhan imanku

5

Aktif

KepadaMu aku memohon nyalakan semangat

Bangkitkan nyali

Robohkan tantangan ombak lautan

Rahasia hidup mesti terpecahkan

Kedua. Koherensi. Koherensi yaitu kata penghubung yang dipakai menyebabkan makna yang berlainan ketika hendak menghubungkan proporsisi. Tujuannya adalah agar kalimat tidak membosankan sehingga perlu dilakukannya dinamisasi oleh penulis dengan menggunakan kata hubung yang bervariasi serta tidak mengubah arti pesan yang akan disampaikan.

Tabel 2: Penggunaan Kata Koherensi

\begin{tabular}{|c|c|c|}
\hline Lirik & Koherensi & Kalimat \\
\hline 1 & Yang & $\begin{array}{l}\text { Banyak cerita } \\
\text { Yang mestinya kau saksikan }\end{array}$ \\
\hline 1 & Tetapi & $\begin{array}{l}\text { Kepada karang kepada ombak } \\
\text { Kepada matahari } \\
\text { Tetapi semua diam } \\
\text { Tetapi semua bisu } \\
\text { Tinggal aku sendiri } \\
\text { Terpaku menatap langit }\end{array}$ \\
\hline 1 & Dan, Dengan & $\begin{array}{l}\text { Mungkin Tuhan mulai bosan } \\
\text { Melihat tingkah kita } \\
\text { Yang selalu salah dan bangga dengan dosa-dosa }\end{array}$ \\
\hline 1 & Atau & $\begin{array}{l}\text { Atau alam mulai enggan } \\
\text { Bersahabat dengan kita }\end{array}$ \\
\hline 1 & Dengan & $\begin{array}{l}\text { Atau alam mulai enggan } \\
\text { Bersahabat dengan kita }\end{array}$ \\
\hline 1 & Yang & $\begin{array}{l}\text { Coba kita bertanya pada } \\
\text { Rumput yang bergoyang }\end{array}$ \\
\hline 2 & Dan & $\begin{array}{l}\text { Kita mesti telanjang } \\
\text { dan benar-benar bersih }\end{array}$ \\
\hline
\end{tabular}

Tabligh: Jurnal Komunikasi dan Penyiaran Islam Vol. 1 No. 1 (2016) 105-128 


$\begin{array}{ll}2 & \text { Yang } \\ 2 & \text { Dan } \\ 2 & \text { Dan } \\ 2 & \text { Yang }\end{array}$

3 Entah

3 Hanya

$3 \quad$ Yang

$3 \quad$ Yang

4 Dan

$4 \quad$ Yang

$4 \quad$ Hanya, Yang

$4 \quad$ Yang

$4 \quad$ Dengan, Yang

4 Dan

5 Dan

Suci lahir dan di dalam batin

Tengoklah ke dalam sebelum bicara

Singkirkan debu yang masih melekat

Kita mesti berjuang memerangi diri

Bercermin dan banyaklah bercermin

Bila masih mungkin kita menorehkan batin

Atas nama jiwa dan hati tulus ikhlas

Kita pasti ingat tragedi yang memilukan

Kenapa harus mereka yang tertimbun tanah

Tentu ada hikmah yang harus kita petik

Atas nama jiwa mari heningkan cipta

Kita mesti bersyukur

Bahwa kita masih diberi waktu

Entah sampai kapan

Tak ada yang bakal dapat menghitung

Hanya atas kasihnya

Hanya atas kehendaknya

Kita masih bertemu matahari

Sampai kapankah gerangan

Waktu yang masih tersisa

Yang terbaik hanyalah segeralah bersujud

Mumpung kita masih diberi waktu

Kemanapun aku pergi

Bayang bayangmu mengejar

Bersembunyi dimanapun

S'lalu engkau temukan

Aku merasa letih dan ingin sendiri

$\mathrm{Ku}$ tanya pada siapa

Tak ada yang_menjawab

Sebab semua peristiwa

Hanya di rongga dada

Pergulatan yang panjang dalam kesunyian

Kemanapun aku pergi

Selalu ku bawa bawa

Perasaan yang bersalah datang menghantuiku

Masih mungkinkah pintumu ku buka

Dengan kunci yang pernah kupatahkan

Lihatlah aku terkapar dan luka

Dengarkanlah jeritan dari dalam jiwa

KepadaMu aku pasrahkan

Seluruh jiwa dan ragaku

Hidup dan mati ada di tanganMu

Bahagia, sedih ada di jariMu

5 Dan

Cukup lama aku mencari

Menembus pekat dan menerjang kelam

$5 \quad$ Yang

Menyusuri langkah yang makin jauh

Tabligh: Jurnal Komunikasi dan Penyiaran Islam Vol. 1 No. 1 (2016) 105-128 


$\begin{array}{lll}5 & \text { Meski } & \begin{array}{l}\text { Adalah firmanMu pemandu jalanku } \\ \text { Batu gunung tetap tegap tegar } \\ \end{array} \\ & \text { Meski angin geram menerpa } \\ & \text { Meski } & \begin{array}{l}\text { Batu karang tak hendak terhempas } \\ \text { Meski ombak menerjang terjang } \\ \text { Rindu keteguhan imanku }\end{array} \\ & \end{array}$

Ketiga. Kata Ganti. Menurut penulis dalam analisis wacana ini kata ganti adalah elemen untuk memanipulasi bahasa dengan menciptakan suatu komunitas imanjinatif. Kata ganti merupakan alat yang dipakai oleh komunikator untuk menujukkan di mana posisi seseorang dalam wacana. Dalam mengungkapkan sikapnya, seseoarang dapat menggunakan "kami" atau "saya" yang menggambarkan bahwa sikap tersebut merupakan sikap resmi komunikator. Namun, ketika menggunakan kata ganti "kita", sikap tersebut sebagai representasi dari sikap bersama dalam suatu komunitas tersebut. pemakian kata ganti yang jamak seperti "kita" (atau"kami")

Van Dijk mempunyai implikasi menumbuhkan solidaritas, aliansi, perhatian, yang pada dasarnya merupakan upaya merangkul dan menghilangkan oposisi yang ada. Pemakian kata ganti "kita" menciptakan komunitas antara wartawan dan para pembaca.

Tabel 3: Penggunaan Kata Ganti dan Kata Asal

\begin{tabular}{lll}
\hline Lirik & \multicolumn{1}{c}{ Kata Ganti } & \multicolumn{1}{c}{ Kata Asal } \\
\hline 1 & Sayang engkau tak duduk & Umum kepada manusia beriman \\
& Disampingku kawan & \\
1 & Tubuhku terguncang & Penyanyi \\
1 & Gembala kecil & Seorang anak penggembala \\
1 & Ketika di kutanya mengapa & Penyanyi \\
1 & Bapak ibunya tlah lama mati & Gambala kecil \\
1 & Kukabarkan semuanya & Gambala kecil \\
1 & Tinggal aku sendiri & Gambala kecil \\
1 & Barangkali di sana ada jawabnya & Di atas langit, Sang Maha Kuasa \\
1 & Mengapa di tanahku terjadi & Gambala kecil \\
& bencana & \\
1 & Mungkin Tuhan mulai bosan & Allah \\
1 & Melihat tingkah kita & Manusia \\
1 & Bersahabat dengan kita & Manusia \\
1 & Coba kita bertanya pada & Manusia
\end{tabular}


1 Rumput yang bergoyang

$2 \quad$ Kita mesti telanjang

2 Tengoklah ke dalam sebelum bicara

2 Anugerah dan bencana adalah kehendakNya

2 Adalah Dia di atas segalanya

2 Bahwa kita mesti banyak berbenah

2 Memang, bila kita kaji lebih jauh

2 Tuhan pasti telah memperhitungkan

2 Amal dan dosa yang kita perbuat

2 Kemanakah lagi kita kan sembunyi

2 Hanya kepadaNya kita kembali Mari, hanya tunduk sujud padaNya Hanya atas kasihNya Hanya atas kehendak Nya $\underline{\text { Kita }}$ masih bertemu matahari
Orang yang menggoyangkan kepalanya saat berdzikir; A'lim Ulama

Diri sendiri

Diri sendiri

Allah

Allah

Manusia

Manusia

Allah

Manusia

Manusia

Allah

Allah

Manusia

Allah

Allah

Manusia

Manusia

Manusia

Korban bencana Alam

Manusia

Manusia

Manusia, Allah

Allah

Manusia 
3 Kita dapat mencoba meminjam catatanNya

3 Semuanya menggeleng

Manusia

Semuanya terdiam

Semuanya menjawab tak mengerti

3 Mumpung kita masih diberi waktu

Manusia

Kemanapun aku pergi

Bayang bayangMu mengejar

Penyanyi

Allah

S'lalu engkau temukan

Allah

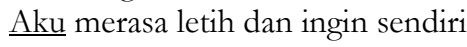

Penyanyi

$\underline{\mathrm{Ku}}$ tanya pada siapa

Penyanyi

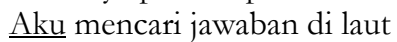

$\underline{\mathrm{Ku}}$ sadari langkah menyusuri pantai

Penyanyi

Aku merasa mendengar suara

$4 \quad$ Kemanapun aku pergi

Penyanyi

Selalu ku bawa bawa

Perasaan yang bersalah datang

menghantuiku

$4 \quad$ Masih mungkinkah pintuMu ku buka

Allah

Dengan kunci yang pernah kupatahkan

Lihatlah aku terkapar dan luka

$\underline{\text { Aku ingin pulang }}$

$5 \quad$ Kepada $\underline{\mathrm{Mu}}$ aku pasrahkan

Penyanyi

Seluruh jiwa dan ragaku

Hidup dan mati ada di tangan $\underline{\mathrm{Mu}}$

Bahagia, sedih ada di jarimu

$5 \quad$ Cukup lama aku mencari

Penyanyi

5 Adalah firmanMu pemandu jalanku

Allah, Penyanyi

Rindu keteguhan imanku

Allah

Penyanyi

Keempat, Stilistik (Pilihan kata yang dipakai). Pusat perhatian stlitistik adalah style (gaya bahasa), yaitu cara yang digunakan seorang pembicara atau penulis untuk menyatakan maksdunya dengan menggunakan bahasa sebagai sarana (Alex Sobur, 2001: 82). Gaya bahasa yang digunakan penulis pada unsur dakwah dalam lirik lagu ini adalah gaya bahasa sastra. Elemen yang diamati Van Dijk adalah gaya bahasa diksi atau pilihan kata (leksikal). Makna kata secara leksikal banyak yang sama, tetapi penggunaannya tidak sama (Cecep Wahyu Hoerudin, 2007: 58) leksikal pada Pesan Dakwah dalam Lirik Lagu sebagai berikut:

Tabel 4: Penggunaan Stlitistik

\begin{tabular}{ll}
\hline Lirik & \multicolumn{1}{c}{ Kalimat } \\
\hline 1 & Tubuhku terguncang \\
\hline
\end{tabular}

Tabligh: Jurnal Komunikasi dan Penyiaran Islam Vol. 1 No. 1 (2016) 105-128 


\begin{tabular}{|c|c|}
\hline & Dihempas batu jalanan \\
\hline & Hati tergetar menatap kering rerumputan \\
\hline \multirow[t]{3}{*}{1} & Tinggal aku sendiri \\
\hline & Terpaku menatap langit \\
\hline & Barangkali di sana ada jawabnya \\
\hline \multirow[t]{4}{*}{1} & Atau alam mulai enggan \\
\hline & Bersahabat dengan kita \\
\hline & Coba kita bertanya pada \\
\hline & Rumput yang bergoyang \\
\hline \multirow[t]{2}{*}{2} & Tengoklah ke dalam sebelum bicara \\
\hline & Singkirkan debu yang masih melekat \\
\hline \multirow[t]{2}{*}{2} & Hanya cambuk kecil agar kita sadar \\
\hline & Adalah Dia di atas segalanya \\
\hline \multirow[t]{5}{*}{2} & Memang, bila kita kaji lebih jauh \\
\hline & Dalam kekalutan, masih banyak tangan \\
\hline & Yang tega berbuat nista \\
\hline & Tuhan pasti telah memperhitungkan \\
\hline & Amal dan dosa yang kita perbuat \\
\hline \multirow[t]{5}{*}{2} & Kita mesti berjuang memerangi diri \\
\hline & Bercermin dan banyaklah bercermin \\
\hline & Tuhan ada di sini di dalam jiwa ini \\
\hline & Berusahalah agar \\
\hline & Dia tersenyum \\
\hline \multirow[t]{2}{*}{3} & Bila masih mungkin kita menorehkan batin \\
\hline & Atas nama jiwa dan hati tulus ikhlas \\
\hline 3 & Atas nama jiwa mari heningkan cipta \\
\hline \multirow[t]{3}{*}{3} & Kita masih bertemu matahari \\
\hline & $\begin{array}{l}\text { Kepada rumpun di lalang kepada bintang } \\
\text { gemintang }\end{array}$ \\
\hline & Kita dapat mencoba meminjam catatanNya \\
\hline \multirow[t]{2}{*}{4} & Kemanapun aku pergi \\
\hline & Bayang bayangmu mengejar \\
\hline \multirow[t]{3}{*}{4} & Sebab semua peristiwa \\
\hline & Hanya di rongga dada \\
\hline & Pergulatan yang panjang dalam kesunyian \\
\hline \multirow[t]{2}{*}{4} & Masih mungkinkah pintumu ku buka \\
\hline & Dengan kunci yang pernah kupatahkan \\
\hline \multirow[t]{2}{*}{5} & Cukup lama aku mencari \\
\hline & Menembus pekat dan menerjang kelam \\
\hline \multirow[t]{5}{*}{5} & Batu gunung tetap tegap tegar \\
\hline & Meski angin geram menerpa \\
\hline & Batu karang tak hendak terhempas \\
\hline & Meski ombak menerjang terjang \\
\hline & Rindu keteguhan imanku \\
\hline 5 & Adalah firmanMu pemandu jalanku \\
\hline 5 & Robohkan tantangan ombak lautan \\
\hline
\end{tabular}


Keempat, retoris (grafis atau ekspresi). Retoris merupakan gaya yang diungkapkan ketika seseorang berbicara atau menulis. Tujuannya, untuk menarik perhatian pembaca akan isi suatu wacana. Pada Pesan Dakwah dalam Lirik Lagu ini menggunakan hiperbola (berlebihan), repitisi (pengulangan), metonimia dan metafora. Retoris yang ada pada Pesan Dakwah dalam Lirik Lagu adalah sebagai berikut:

Tabel 4. Penggunaan Retoris

\begin{tabular}{|c|c|c|}
\hline Lirik & Retoris & Kalimat \\
\hline 1 & Ekspresi & $\begin{array}{l}\text { Perjalanan ini } \\
\text { Terasa sangat menyedihkan }\end{array}$ \\
\hline 1 & Metonimia & $\begin{array}{l}\text { Tubuhku terguncang } \\
\text { Dihempas batu jalanan }\end{array}$ \\
\hline 1 & Hiperbola & Hati tergetar menatap kering rerumputan \\
\hline 1 & Ekspresi & $\begin{array}{l}\text { Gembala kecil } \\
\text { Menangis sedih }\end{array}$ \\
\hline 1 & Metafora & $\begin{array}{l}\text { Bapak ibunya tlah lama mati } \\
\text { Ditelan bencana tanah ini }\end{array}$ \\
\hline 1 & Hiperbola & $\begin{array}{l}\text { Terpaku menatap langit } \\
\text { Barangkali di sana ada jawabnya }\end{array}$ \\
\hline 1 & Litotes & $\begin{array}{l}\text { Mungkin Tuhan mulai bosan } \\
\text { Melihat tingkah kita } \\
\text { Yang selalu salah dan bangga dengan dosa-dosa }\end{array}$ \\
\hline 1 & Paradoks & $\begin{array}{l}\text { Atau alam mulai enggan } \\
\text { Bersahabat dengan kita }\end{array}$ \\
\hline 1 & Personifikasi & $\begin{array}{l}\text { Coba kita bertanya pada } \\
\text { Rumput yang bergoyang }\end{array}$ \\
\hline 2 & Repetisi & $\begin{array}{l}\text { Kita mesti telanjang } \\
\text { dan benar-benar bersih } \\
\text { Suci lahir dan di dalam batin }\end{array}$ \\
\hline 2 & Metafora & $\begin{array}{l}\text { Tengoklah ke dalam sebelum bicara } \\
\text { Singkirkan debu yang masih melekat }\end{array}$ \\
\hline 2 & Alegori & $\begin{array}{l}\text { Hanya cambuk kecil agar kita sadar } \\
\text { Adalah Dia di atas segalanya }\end{array}$ \\
\hline 2 & Repitisi & Anak menjerit-jerit, asap panas membakar \\
\hline 2 & Metafora & $\begin{array}{l}\text { Lahar dan badai menyapu bersih } \\
\text { Ini bukan hukuman, hanya satu isyarat } \\
\text { Bahwa kita mesti banyak berbenah }\end{array}$ \\
\hline 2 & Hiperbola & $\begin{array}{l}\text { Tuhan pasti telah memperhitungkan } \\
\text { Amal dan dosa yang kita perbuat }\end{array}$ \\
\hline 2 & Repitisi & Bercermin dan banyaklah bercermin \\
\hline
\end{tabular}


Syifa Hayati Islami

\begin{tabular}{|c|c|c|}
\hline 2 & Ekspresi & $\begin{array}{l}\text { Tuhan ada di sini di dalam jiwa ini } \\
\text { Berusahalah agar }\end{array}$ \\
\hline \multirow{2}{*}{2} & Ekspresi & Kita pasti ingat tragedi vang memilukan \\
\hline & & Kenapa harus mereka yang tertimbun tanah \\
\hline \multirow[t]{3}{*}{2} & Klimaks & Kita masih bertemu matahari \\
\hline & & Kepada rumpun di lalang kepada bintang gemintang \\
\hline & & Kita dapat mencoba meminjam catatanNya \\
\hline \multirow[t]{3}{*}{2} & Pararelisme & Semuanya menggeleng \\
\hline & & Semuanya terdiam \\
\hline & & Semuanya menjawab tak mengerti \\
\hline \multirow[t]{4}{*}{4} & Hiperbola & Kemanapun aku pergi \\
\hline & & Bayang bayangmu mengejar \\
\hline & & Bersembunyi dimanapun \\
\hline & & S'lalu engkau temukan \\
\hline \multirow[t]{3}{*}{4} & Personifikasi & Sebab semua peristiwa \\
\hline & & Hanya di rongga dada \\
\hline & & Pergulatan yang panjang dalam kesunyian \\
\hline \multirow[t]{2}{*}{4} & Hiperbola & Lihatlah aku terkapar dan luka \\
\hline & & Dengarkanlah jeritan dari dalam jiwa \\
\hline \multirow[t]{4}{*}{5} & Klimaks & Cukup lama aku mencari \\
\hline & & Menembus pekat dan menerjang kelam \\
\hline & & Menyusuri langkah yang makin jauh \\
\hline & & Adalah firmanMu pemandu jalanku \\
\hline \multirow[t]{4}{*}{5} & Repetisi & Batu gunung tetap tegap tegar \\
\hline & & Meski angin geram menerpa \\
\hline & & Batu karang tak hendak terhempas \\
\hline & & Meski ombak menerjang terjang \\
\hline \multirow[t]{2}{*}{5} & Personifikasi & Robohkan tantangan ombak lautan \\
\hline & & Rahasia hidup mesti terpecahkan \\
\hline
\end{tabular}

Lirik-lirik lagu Ebiet G. Ade merupakan sebuah totalitas sehingga mempunyai bagian-bagian, unsur-unsur, yang saling berkaitan yang satu dengan yang lainnya secara erat dan juga saling keterkaitan dalam struktur mikro, keterkaitan tersebut terjalin antara unsur semantik, sintksis, stlitistik, dan retoris pada setiap wacananya.

Dari data tersebut, gaya bahasa yang terkandung pada setiap lirik-lirik lagu Ebiet G. Ade mengandung bahasa yang indah dalam menyampaikan unsur ketauhidan yang dikemas sebagai pesan dakwah. Maka dari itu tujuannya tak lain hanyalah agar materi dakwah ini mudah diterima dan dicerna oleh khalayak umum melalui lirik-lirik lagu yang di senandungkan oleh Ebiet G. Ade. 


\section{PENUTUP}

Setelah dilakukan analisis mengenai unsur dakwah dalam lirik lagu ini, penulis dapat menyimpulkannya Struktur makro sebuah teks yang berkaitan dengan makna global/umum dari suatu teks dengan melihat topik/tema dari suatu teks tersebut. Inti pesan yang ingin lenulis sampaikan pada unsur dakwah dalam lirik lagu ini yaitu satu pokok tentang ketauhidan yakni menyangkut dengan masalah keimanan terhadap Allah Swt., yang menjamin kehidupan setiap orang, sebagai tempat untuk bersandar, dan tiada tempat bergantung selain pada-Nya. Tema ketauhidan ini menjadikan kesadaran terhadap Allah Swt. atas keberadaan-Nya sehingga kita bisa hidup seperti sekarang ini. Atas segala keni'matannya pula kita diberikan ni'mat agung dalam keislaman juga iman terhadap Allah Swt.

Superstruktur bersifat skematik yang menunjukkan kerangka suatu teks, yakni bagaimana struktur dan elemen wacana itu disusun dalam teks secara utuh. Unsur dakwah tentang ketauhidan ini ada tiga macam, yaitu uluhiyah, ubudiyah dan rububiyah. Super struktur ini menggambarkan bentuk umum dari suatu teks dengan sejumlah kategori atau pembagian umum seperti pendahuluan, isi, pemecahan masalah, kesimpulan, penutup. Struktur mikro terdiri dari analisis linguistik, yakni semantik, sintaksis, stilistik dan retoris.

\section{DAFTAR PUSTAKA}

Abdurrahman al-Baghdadi, (1991). Seni dalam Pandangan Islam, Jakarta: Gema Insan Press.

Al-Bahy, M. (1997). Islam Agama Dakwah Bukan Revolusi, Jakarta: Kalam Mulia,

Al-Maraghi, S. M. Tafsir al-Maraghi, jilid V, juz 13, hal. 1260

Aripudin, A., \& Ridwan, M. R. (2009). Materi Dakwah pada Grup Ban Non-Religi (Analisis Pesan Dakwah dalam Lirik Lagu Grub Band GIGI). Ilmu Dakwah: Academic Journal for Homiletic Studies 4 (13) 493512

Asmuni, M. Y. (1989), Ilmu Taubid, Jakarta: PT.RajaGrafindo.

Chaer, A. (2007). Linguistik Umum. Jakarta: Rineka Cipta.

Depag RI. (2004). Al-Qur'an dan Terjemahnya, Bandung: CV penerbit J-ART. Ebit G Ade, (2016). Bermusik Karena Tak Ada Kegiatan Lain". Minggu Pagi

Online. (Diakses tanggal 20-05-2016) 
Syifa Hayati Islami

Eriyanto. (2001). Analisis Wacana, Pengantar Analisis Teks Media, Yogyakarta

Fatoni, U. (2014). Respon Da'i terhadap Gerakan Jemaat Ahmadiyah Indonesia (JAI) di Tenjowaringin Tasikmalaya. Jurnal Dakwah 15 (1), 49-65

Kabar Indonesia. (2016) Ebiet G. Ade Kembali Mambaca Tanda Zaman Lewat Album Baru. Kabar Indonesia. (Diakses tanggal 20-05-2016)

Kuntowijoyo, (2001). Muslim tanpa masjid, Bandung: Mizan.

Kusnawan, A. (2009). Dimensi Ilmu Dakwah, Bandung: Widya Padjajaran.

Nooryan, B. (2008). Kritik Seni, Yogyakarta: Pustaka Pelajar.

Shihab, A. (1999). Islam Inklusif, Bandung: Mizan.

Shihab, M. Q. (1998). Membumikan Al-Qur'an, Bandung: Mizan.

Sobur, A. (2004). Analisis Teks Media, Bandung; Rosdakarya.

Sukayat, T. (2009). Quantum Dakwah, Jakarta: Rineka Cipta. 